\title{
ACUTE LESION OF THE MOTOR BRANCH OF THE ULNAR NERVE IN THE WRIST AFTER TUG-OF-WAR TRAINING
}

\author{
Vladimir Ferreira Seguti ${ }^{1}$, Aloísio Fernandes Bonavides Júnior ${ }^{2}$, Leandro Pretto Flores ${ }^{3}$, Lisiane Seguti Ferreira ${ }^{4}$
}

\section{ABSTRACT}

Papers correlating clinical and electrophysiological findings relating to ulnar nerve lesions in the wrist are uncommon in the literature, if compared with elbow injuries. We present the case of a patient with atrophy of the intrinsic musculature of the hand, secondary to injury only of the motor branch of the ulnar nerve, which is located in Guyon's canal close to the hamate hook. We review the anatomical, clinical and neu- rophysiological aspects of distal ulnar nerve injuries and we emphasize the importance of multidisciplinary approaches. Specifically in relation to the mechanism of injury of this patient (tug-of-war), we did not find any similar cases in the literature. We issue an alert regarding the risks during military physical training.

Keywords - Ulnar Nerve/anatomy \& histology; Ulnar Nerve/ injuries; Military

\section{INTRODUCTION}

Ulnar nerve entrapment is the second most common entrapment in the upper extremity; however, acute ulnar neuropathy, located distally, is an unusual condition $^{(1)}$. The correlation between electrophysiological and surgical findings of ulnar nerve lesions in the wrist is not frequent in literature, when compared to the description of elbow injuries ${ }^{(2)}$.

The aim of this study is to present the case of ulnar nerve lesion, located distally, and to make a brief review of the main anatomical, clinical and neurophysiological aspects of the distal lesion of this nerve, besides warning of the risks of injury during military physical training.

\section{CLINICAL CASE}

Male, age 42, soldier, serving in the National Force of Luziânia, Goiás. He was in physical training for three months, when he suffered trauma in the right hand, while participating in a tug of war competition. The patient did not hit or fall with his wei- ght on his hand, but merely exerted compression and drag force on the rope. He presented sudden pain and weakness in the palm of the right hand, discontinuing the training.

He sought medical advice, three days after the trauma, and was medicated with non-hormonal anti-inflammatory drugs. The pain improved, yet the patient evolved with inability to move the fingers, as well as loss of muscle trophism in the dorsal region of the right hand. There was no report of local edema. He denied sensory complaints in the hand and forearm. The orthopedist requested a radiograph and ultrasonography of the hand, which were normal, besides electroneuromyography (ENMG). There was no evidence of fracture.

The ENMG showed a normal sensory nerve conduction study and the motor nerve conduction study with important reduction in compound muscle action potential amplitude (difference of over $90 \%$ in relation to the contralateral homologous muscle), exclusively when captured in the first dorsal interosseous muscle (Figure 1). The needle

1 - Orthopedist of the Federal District Health Department - Brasília, DF, Brazil.

2 - Orthopedist of the Federal District Health Department; Professor of the Medical Course of Escola Superior de Ciências da Saúde do Distrito Federal - Brasília, DF, Brazil.

3 - Neurosurgeon of the Federal District Health Department - Brasília, DF, Brazil.

4 - Clinical Neurophysiologist of the Federal District Health Department; Professor of the Medical Course of Universidade de Brasília - Brasília, DF, Brazil.

Mailing address: Aloísio Fernandes Bonavides Júnior - SEPS 712/912. Edifício Pasteur, Bloco I, Sala 111 - 70390-125 - Brasília, DF. Email: aloisiobonavides@hotmail.com Study received for publication: 1/14/2011, accepted for publication: 3/22/2011.

The authors declare that there was no conflict of interest in conducting this work 
examination evidenced signs of active denervation and recruitment of just two motor unit potentials in the first dorsal interosseous muscle (Figure 2). The other muscles evaluated were normal. These findings were compatible with ulnar neuropathy, of axonal impairment, involving exclusively the motor branch, located close to the pisi-unciform hiatus. With the electrophysiological alterations described and according to the classification proposed by $\mathrm{Wu}$ et $a l^{(3)}$ (Chart 1), the patient was categorized as a type IV lesion.

The ENMG, performed 30 days later, remained unchanged. In the orthopedic revaluation, the health professionals opted for expectant manage-

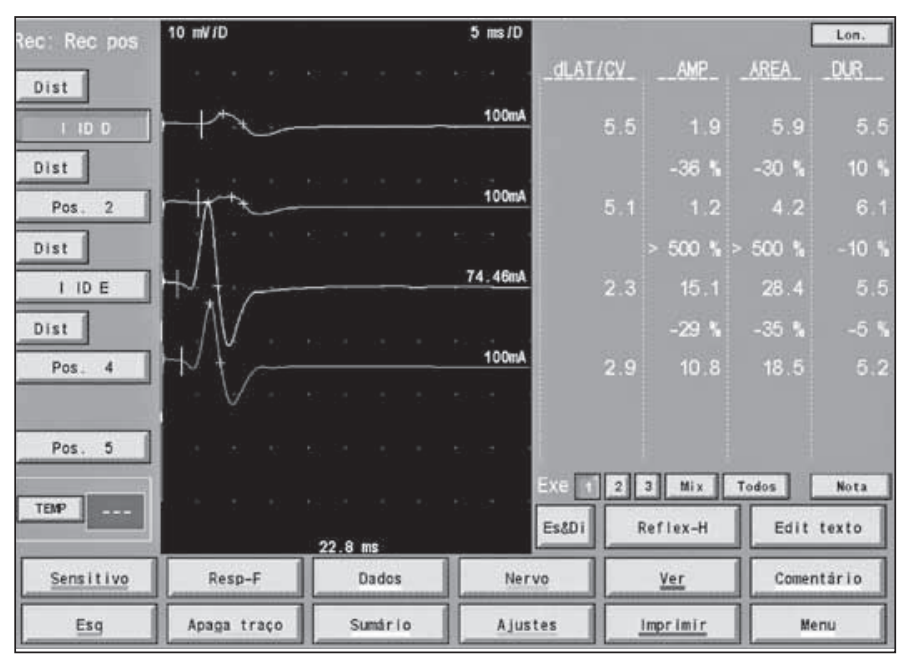

Figure 1 - Observe the compound muscle action potential (CMAP) captured in the first dorsal interosseous muscle - upper line (green) with amplitude of 1.9 and compare with the contralateral CMAP (third line in yellow), corresponding to a decrease close to $90 \%$.

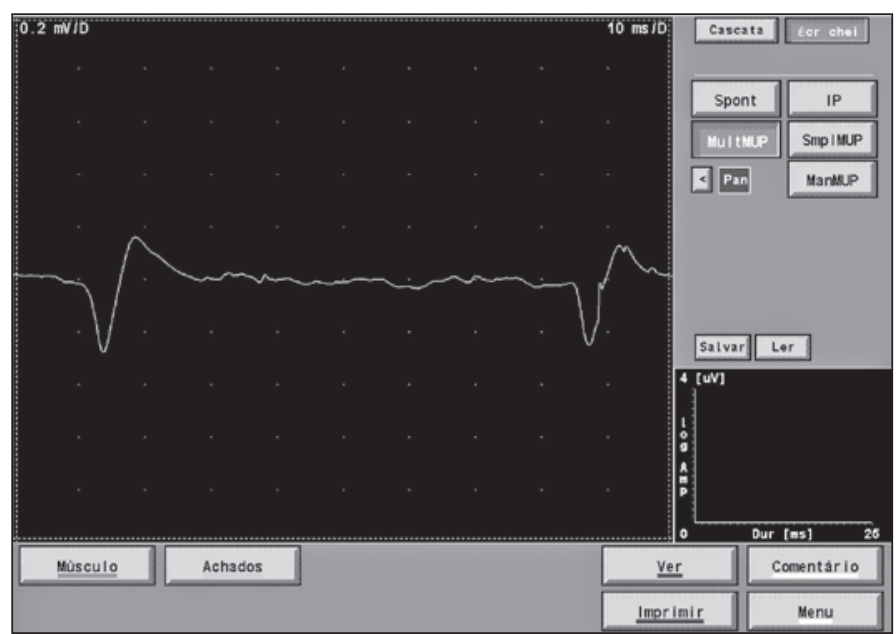

Figure 2 - Recruitment significantly reduced upon exertion. Only two motor unit potentials were recorded here. ment and suggested neurological evaluation. The neurological examination evidenced muscle atrophy, degree IV strength of the intrinsic muscles of the hand, with degree V strength of the abductor muscle of the little finger and normal hand sensitivity. The patient was questioned about the existence of a narrow band of hypoesthesia in the territory of $\mathrm{C} 5$ in the right upper limb and debatable difficulty in abducting the right arm.

The patient had an MRI scan of the cervical spine and brachial plexus, which were normal. There was a third ENMG with a study of more than three segments, in order to rule out the possibility of involvement of the anterior horn of the spinal cord. The ENMG confirmed the selective involvement of the motor branch of the ulnar nerve. The patient was referred for neurosurgical evaluation due to the absence of improvement.

The professionals then opted for the surgical procedure, performed six months after the trauma. The initial intention was to verify the lesion site in situ, and to carry out the necessary decompression and/or correction procedures to reestablish ulnar nerve integrity.

After the application of the pneumatic tourniquet, an incision was made in the wrist, between the pisiform bone and the hamate hook (Figure 3). The palmar carpal ligament was dissected, providing a view of the pisohamate ligament that was thickened, followed by the complete sectioning of this ligament, with the surgeon observing an area of probable compression (pseudoneuroma) with increase in the nerve thickness (Figures 4 and 5).

No deformities such as bone calluses, poor alignment of possible pisiform or hamate fractures, cysts or tumors were verified after decompression further forward in the deep branch of the ulnar nerve. It was decided not to perform epineurolysis due to the fact that the compression was caused by alterations in the surrounding ligaments and tissues. The patient was reassessed 12 months subsequent to the surgical procedure and after physiotherapy, with almost complete recovery of muscle strength and absence of hypotrophy (Figure 6). 


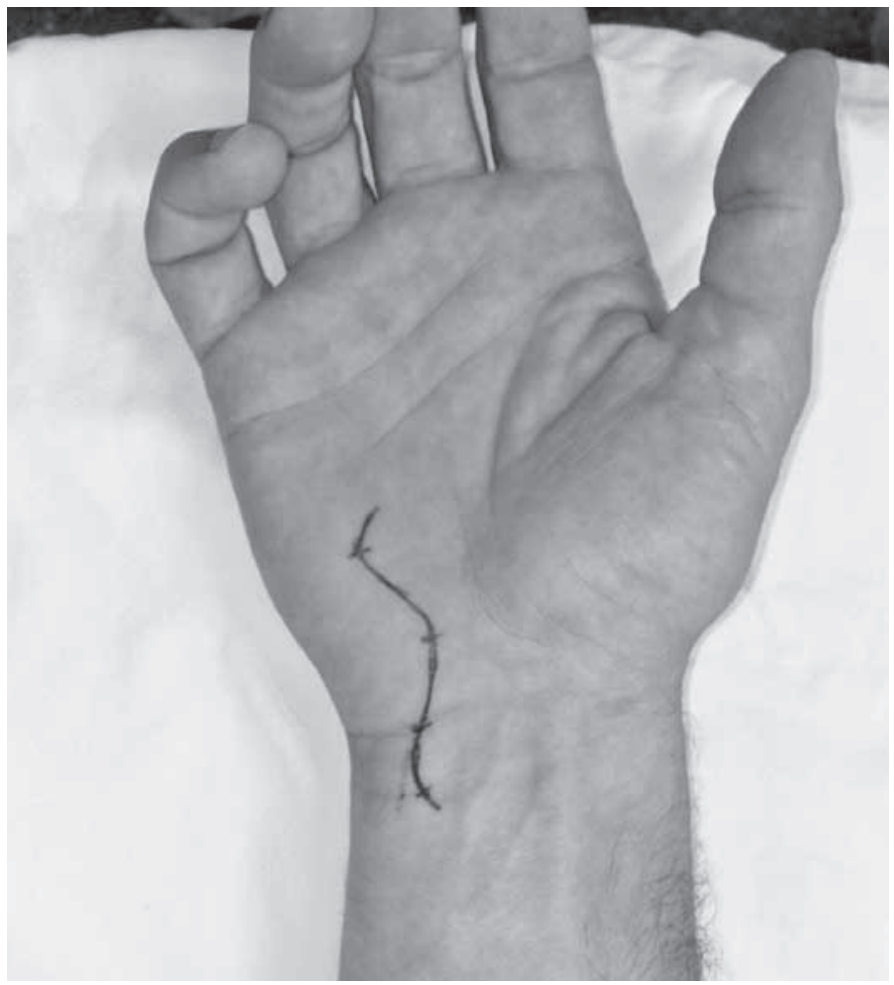

Figure 3 - Planning of surgery.

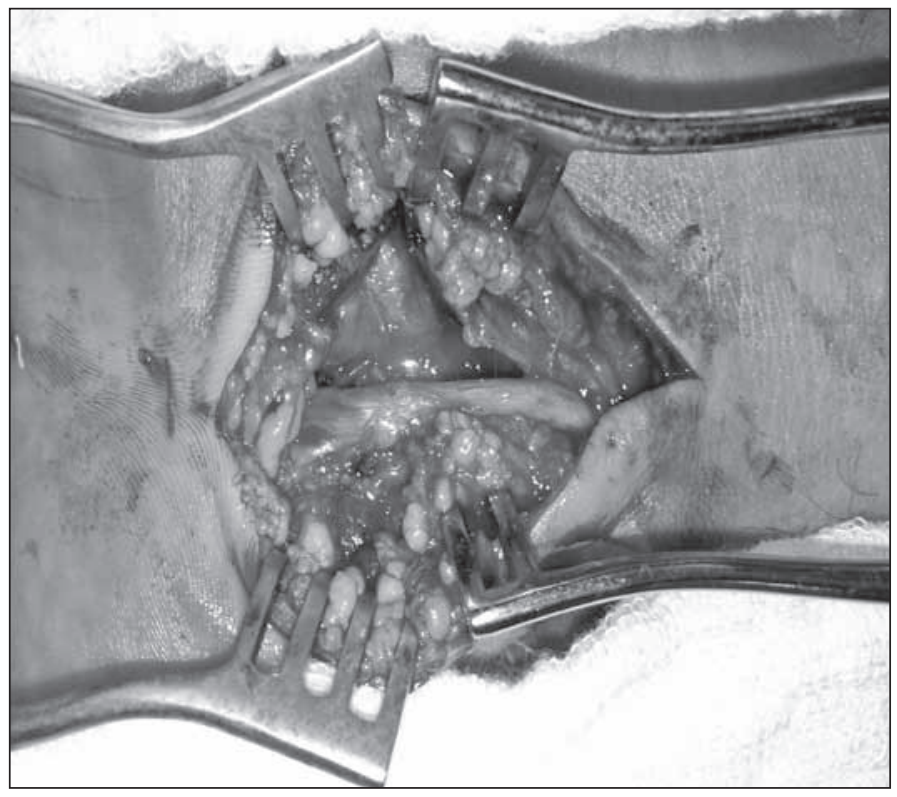

Figure 4 - The ulnar nerve was dissected at the wrist and the deep branch was followed up to the point of entry of the pisohamate hiatus, where proximal ingurgitation of the nerve was observed (pseudoneuroma).

\section{DISCUSSION}

The ulnar nerve is the second most severely impaired nerve in compression syndromes of the upper limb, and proximal involvement in the elbow is much more common ${ }^{(2,4,5)}$.

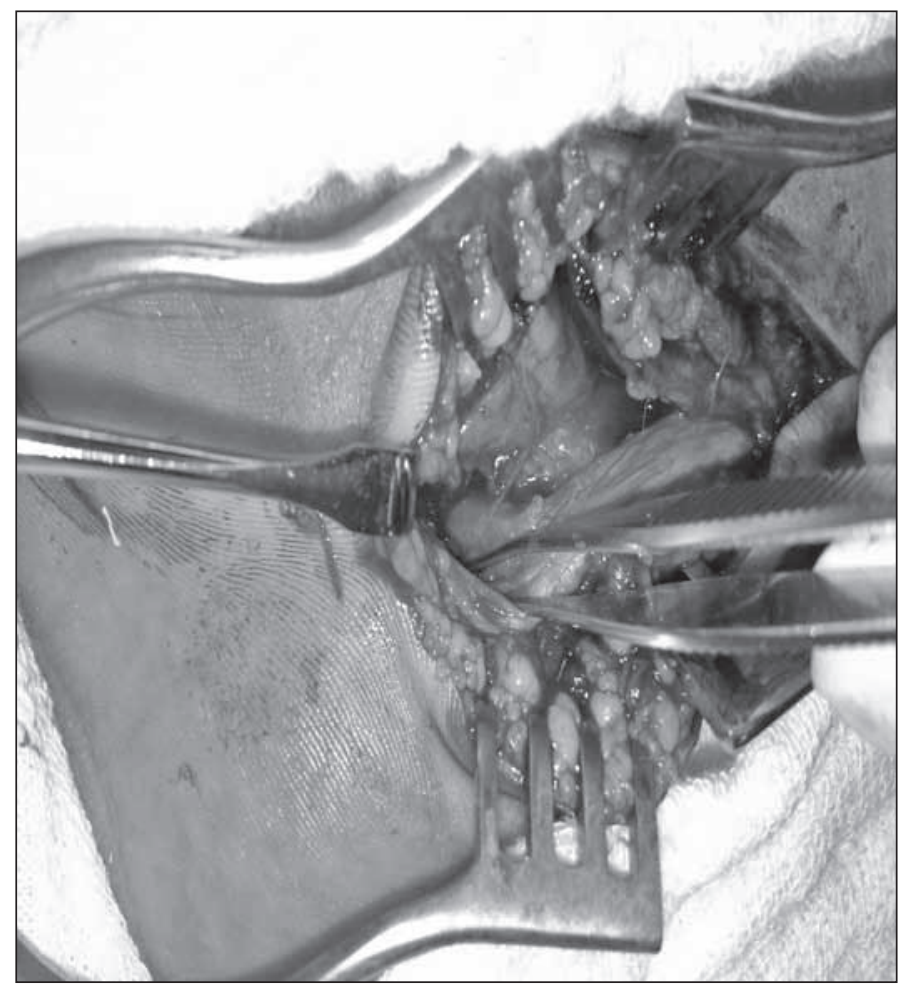

Figure 5 - Performance of decompression in the deep branch of the ulnar nerve, followed by complete sectioning of the pisohamate ligament.

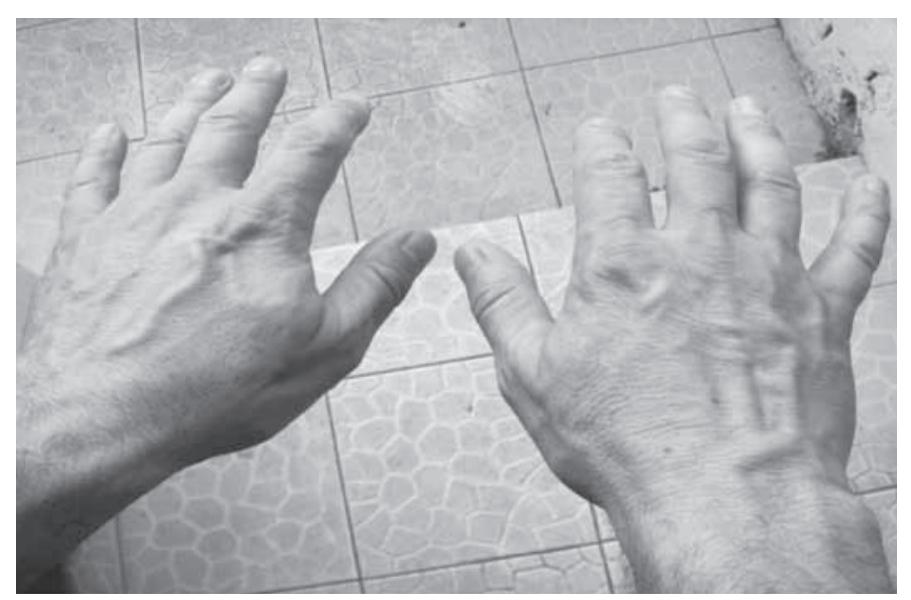

Figure 6 - There are no signs of hypotrophy one year after the surgical procedure.

We documented the patient's clinical and electrophysiological findings, without evidence of fracture, presenting acute lesion of the ulnar nerve, of distal location, involving only its motor branch. Besides being uncommon in this topography, we stress that there is no record of similar cases in literature, specifically with this mechanism of injury (tug of war).

The tug of war or rope pulling is a sport in which two teams compete against each other in a test of strength, pulling a rope. The sport was part of the 
Olympic Games from 1900 to 1920 and is regulated by the Tug of War International Federation - TWIF $^{(6)}$. However, as is the case of other sports, tug of war training can entail dislocations, sprains and fractures ${ }^{(7)}$.

Studies have been conducted on the occurrence of injuries during military physical training, which mainly involve the knee and the ankle and are more often related to running. The occurrence of these injuries has served as a warning as regards choice, correct method and intensity in the execution of exercises ${ }^{(8)}$. The risk of the patient under analysis evolving to claw hand on the right side (dominant hand) as a sequela could not be disregarded in this context.

In dealing with a patient with claw hand, the investigation should include the following possibilities: brachial plexopathy, C8/T1 radiculopathy, cervical syringomyelia, thoracic outlet syndrome, Hirayama syndrome, multifocal neuropathy, Hansen's disease leading to amyotrophic lateral sclerosis, among others ${ }^{(9)}$.

The patient's diagnosis was facilitated by the thorough electrophysiological study, which identified injury of the ulnar nerve with exclusive involvement of the motor branch. NMRs of the cervical spine and brachial plexus were requested in addition to the ENMG of the four limbs, as the patient also presented complaints of weakness in the arm.

The clinical presentation of ulnar nerve lesions shows variation due to the complex anatomical course of the nerve at its most distal sites, which hinders semiological and electrophysiological interpretation, resulting in diagnostic challenge ${ }^{(4,5)}$.

In Guyon's canal, the ulnar nerve can be com-

\section{REFERENCES}

1. Elhassan B. Entrapment neuropathy of the ulnar nerve. J Am Acad Orthop Surg. 2007;15(11):672-81.

2. Papathanasiou ES, Loizides A, Panayiotou P, Papacostas SS, Kleopa KA. Ulnar neuropathy at Guyon's canal: electrophysiological and surgical findings. Electromyogr Clin Neurophysiol. 2005;45(2):87-92.

3. Wu JS, Morris JD, Hogan GR. Ulnar neuropathy at the wrist: case report and review of literature. Arch Phys Med Rehabil. 1985;66(11):785-8.

4. Erkin G, Uysal H, Keles I, Aybay C, Ozel S. Acute ulnar neuropathy at the wrist: a case report and review of the literature. Rheumatol Int. 2006;27(2):191-6.

5. Pearce C, Feinberg J, Wolfe SW UInar neuropathy at the wrist. HSS J. 2009; 5(2):180-3.

6. TWIF rules manual 2009/2010. Twif Tug of War International Federation. Disponível em: http://www.tugofwar-twif.org

7. Rettig AC. Athletic injuries of the wrist and hand. Part I: traumatic injuries of the wrist. Am J Sports Med. 2003;31(6):1038-48.

8. Gonçalves EM, Silva RR. Principais lesões decorrentes do treinamento físico pressed along its course, producing sensory, motor or mixed deficits. The deep branch innervates the hypothenar muscles, including the abductor of the fifth finger, and travels through the palm to the dorsal and palmar interossei, the third and fourth lumbricals, the thumb adductor muscle and part of the short flexor of the thumb. The short flexor of the fifth finger, hypothenar muscle, has two separate fixations, in the unciform bone and in the pisiform bone. These musculocutaneous fixations form a fibrous arch and create the superficial limits of the pisi-unciform hiatus, site of the patient's lesion ${ }^{(9,10)}$.

Almost half of the injuries occur secondarily to acute or chronic trauma, mainly related to the type of occupation ${ }^{(10,11)}$. Ganglion cysts are the second most common cause; but, in these cases, the isolated compression of the deep motor branch alone is uncommon, particularly in those that present fast evolution, severe and progressive nature of the compression signs and symptoms ${ }^{(12)}$.

The conduct indicated in patients with fractures, cysts or expansive processes is surgery. Clinical and electrophysiological control is performed in the other cases. The absence of improvement after conservative treatment and clinical deterioration is indicative of surgical intervention ${ }^{(13)}$. After decompression, the prognosis is usually good, as the lesion is distal and targeted hand muscle reinnervation is efficient ${ }^{(14)}$.

Finally, the favorable evolution of the case described here illustrates the importance of follow-up by different specialists, since the patient could have evolved with permanent ulnar claw. It also serves as a warning with regards to the risks during the physical training of soldiers, which emphasizes the criterion in the selection and intensity of the exercises applied.

militar no Centro Integrado de Guerra Eletrônica - Departamento de Ciência e Tecnologia do Exército Brasileiro. Rev Educ Física. 2008;2(3):1-11.

9. Dumitri D, Amato A, Zwarts, M. Eletrodiagnostic medicine. 2nd ed. Philadelphia: Hanley \& Belfus; 2004.

10. Monein MS: Ulnar nerve compression at the wrist: ulnar tunnel syndrome. Hand Clinics. 1992;8:337-44.

11. Haferkamp $\mathrm{H}$. Ulnar nerve compression in the area of the wrist. Langenbecks Arch Chir Suppl Kongressbd. 1998;115:635-40.

12. Inaparthy PK, Anwar F, Botchu R, Jähnich H, Katchburian MV. Compression of the deep branch of the ulnar nerve in Guyon's canal by a ganglion: two cases. Arch Orthop Trauma Surg. 2008;128 (7): 641-3.

13. Blecher R, Loebenberg M, Oron A. Ulnar Entrapment Neuropathy. Hareafuah. 2010;149(2):104-7.

14. Zöch G, Meissl G, Millesi H. Results of decompression of the ulnar nerve in Guyon's canal] Handchir Mikrochir Plast Chir. 1990;22(3):125-9. 